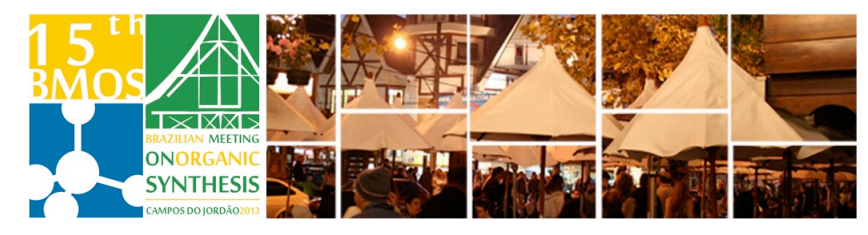

\title{
Metal-catalyzed direct carboxylation of unactivated alkyl halides with $\mathrm{CO}_{2}$
}

\section{Yu Liu and Ruben Martin*}

Av. Països Catalans 16, 43007 Tarragona, Spain

rmartinromo@iciq.es; yuliu@iciq.es

carbon dioxide; alkyl halide; carboxylation

\section{INTRODUCTION}

The exploitation of carbon dioxide as a C1 source has attracted much attention due to the fact that it is a renewable, inexpensive, nontoxic and environment-friendly carbon feedstock. ${ }^{1}$ In recent years, the catalytic carboxylation of arylmetal species, alkynes and activated $\mathrm{C}-\mathrm{H}$ bonds has been well documented in the literature. ${ }^{1} \mathrm{We}^{2 \mathrm{a}}$ and others ${ }^{2 \mathrm{~b}}$ have also developed the carboxylation of aryl halides with $\mathrm{CO}_{2}$ leading to benzoic acids. Recently, we described the first catalytic carboxylation of primary, secondary and tertiary benzyl halides with $\mathrm{CO}_{2}$ en route to phenylacetic acids (Figure 1). ${ }^{3}$ Despite the advances realized, to the best of our knowledge the direct carboxylation of unactivated alkyl halides ${ }^{4}$ with $\mathrm{CO}_{2}$ has not been reported.

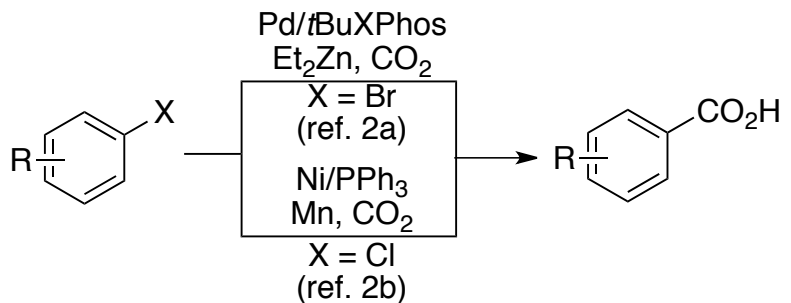

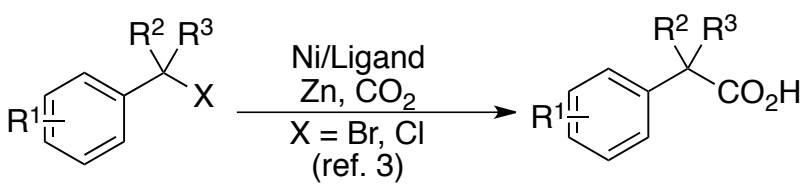

Figure 1. Metal-catalyzed carboxylation of aryl or benzyl halides with $\mathrm{CO}_{2}$.

\section{RESULTS AND DISCUSSION}

We chose differently substituted unactivated alkyl halides to study a catalytic carboxylation event via dual activation of alkyl halides and $\mathrm{CO}_{2}$. Based on the experience of our laboratories in catalytic $\mathrm{CO}_{2}$ activation, ${ }^{2,3}$ the effect of catalysts, reducing agents, additives and solvents were systematically examined. After careful screening of the reaction conditions, we finally found appropriate conditions that allowed us to deliver the targeted aliphatic carboxylic acids in good yields. Importantly, the proclivity of the in situ formed alkyl metal species towards reductive elimination was significantly retarded by ligand modulation. Likewise, the finetuning of the reaction conditions suppressed other side-reactions such as the reduction of the parent alkyl halide. Importantly, the protocol is distinguished by its wide substrate scope and mild conditions, allowing for the coupling of different alkyl halides in good to excellent yields in the presence of rather sensitive functional groups.

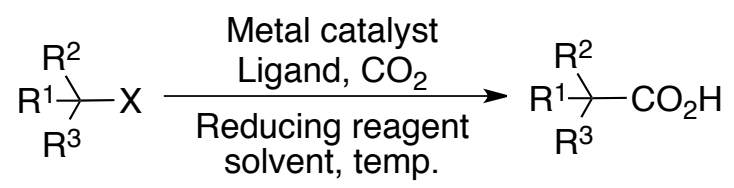

Figure 2. Metal-catalyzed carboxylation of unactivated alkyl halides with $\mathrm{CO}_{2}$.

\section{CONCLUSION}

In conclusion, we have developed a novel and straightforward metal-catalyzed carboxylation reaction of unactivated alkyl halides with $\mathrm{CO}_{2}$, leading to a series of carboxylic acids in good yields. Further investigations are ongoing in our laboratories.

\section{ACKNOWLEDGEMENTS}

We thank the ICIQ Foundation, the European Reasearch Council (ERC-277883), and MICINN (CTQ2012-34054) for financial support.

\section{REFERENCES}

${ }^{1}$ For selected reviews, see: (a) Cokoja, M.; Bruckmeier, C.; Rieger, B.; Herrmann, W. A.; Kühn, F. E. Angew. Chem. Int. Ed. 2011, 50, 8510. (b) Correa, A.; Martin, R. Angew. Chem. Int. Ed. 2009, 48, 6201. (c) Sakakura, T.; Choi, J.-C.; Yasuda, H. Chem. Rev. 2007, 107, 2365.

2 (a) Correa, A.; Martin, R. J. Am. Chem. Soc. 2009, 131, 15974. (b) Fujihara, T.; Nogi, K.; Xu, T.; Terao, J.; Tsuji, Y. J. Am. Chem. Soc. 2012, $134,9106$.

${ }^{3}$ Leon, T.; Correa, A.; Martin, R. J. Am. Chem. Soc. 2013, 135, 1221.

4 For selected reviews on the activation of alkyl halides, see: (a) Rudolph, A.; Lautens, M. Angew. Chem., Int. Ed. 2009, 48, 2656. (b) Frish, A. C.; Beller, M. Angew. Chem., Int. Ed. 2005, 44, 674 